\title{
Design of Storm Water Drainage System in A Metropolitan Area
}

\author{
Pooja N. Patel* \\ Water Recourse Engineering, \\ L.D. Collage of Engineering and Technology, \\ Ahmedabad, India.
}

\author{
Mr. Utkarsh Nigam \\ Water Recourse Engineering, \\ L. D. Collage of Engineering and Technology, \\ Ahmedabad, India.
}

\author{
Mr. N. N. Borad \\ Water Recourse Engineering, \\ L. D. Collage of Engineering and Technology, \\ Ahmedabad, India.
}

\begin{abstract}
A scientific drainage system to catch the storm water is a long term need of the society, particularly in cities. Urbanization along with its impermeable structures is one of the major causes of flooding in metropolitan areas. The rainfall intensity and characteristics of catchment area are the major factors for designing metropolitan storm water drainage facilities. These facilitates have a uppermost advantage to safely dispose the generated floods to receiving system. Many towns lack in providing proper drainage system. The present design helps the rainfall in design storm water drainage system. Past record of 34 years rainfall data has been taken for study. Various methods were reported in literature for runoff estimation. In the present study, rational method has been used for estimation of storm water runoff which is widely reported in literature. The present study is to estimate runoff of a drainage basin and also to design as a case study for Navrangpura Area in Ahmedabad, Gujarat where the design is based on different velocities .
\end{abstract}

Keywords:- Drainage, Rational method, Runoff, Storm water.

\section{INTRODUCTION}

Storm water drainage is the process of draining excess water from streets, sidewalks, roofs, buildings and other areas. A system which use to drain storm water at various places it has different names like sewers and drainage wells. Storm water can be any rainfall, such as rain, snow and sleet that falls on the surface of the earth. Structural measures to control storm water include storage reservoirs, flood embankments, drainage channels, anti- erosion works, channel improvement works, pipe cleaning work, detention basins and non-structural measures include flood forecasting, flood plain zoning, flood proofing, disaster preparedness etc

In areas with natural ground water, about $10 \%$ of the precipitation becomes runoff and about $50 \%$ infiltrates into the soil to form or replenish ground water and flows into streams. Evaporation and uptake by plants accounts to the remaining $40 \%$. When natural conditions change due to development, land use and other activities, this water cycle becomes altered .As the land becomes more covered with impervious surfaces, more rainfall converts as runoff. This

runoff carries the dust, other loads, and pollutants When the development is more as much as $55 \%$ may become runoff.

Storm sewers (also storm drains) are large pipes or open channels that transport storm water runoff from streets to natural bodies of water, to avoid street flooding. Storm drains vary in design from small residential dry wells to wide municipal systems. various storm drainage systems are designed to drain the storm water, untreated, into rivers or streams. A combined sewer is a type of sewer system that collects sanitary sewage and storm water runoff in a same system. Combined sewers can cause serious water pollution problems due to combined sewer overflows, which are caused by big variations in flow between dry and wet weather.

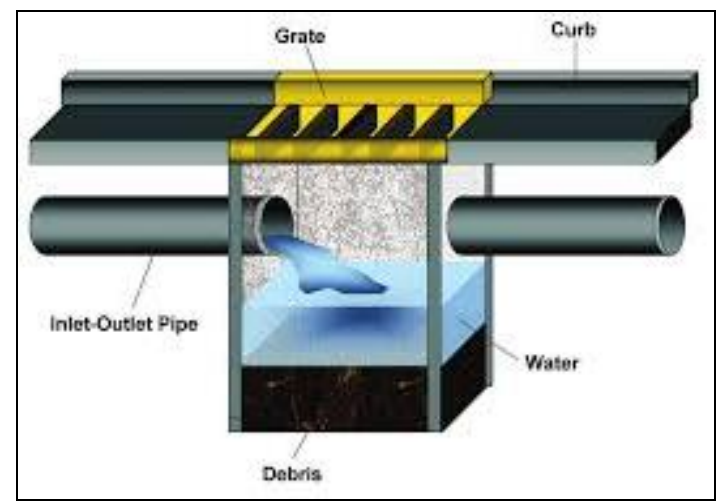

Figure 1: Strom water catch basin. 
Any storm drain in the area may be discharging various quantity of water and also the type of pollutants it contributes. Since the metropolitan cities becoming densely populated, the per-household volumes of waste water exceed the infiltration capacity of local soils and hence require greater drainage capacity and the introduction of sewer systems.

Navrangpura is an area in Ahmedabad-Gujarat population is increasing day by day due to its increased population and commercial activities are also increasing. The drainage system in Navrangpura is through pipe lines. All domestic wastewater generated in the basin is discharged through pipes and flow at river. These pipes have various problems like improper slope, erosion, leakage and self cleaning velocities. The leakage flow creates stagnation of the sewage, creates odour nuisance, and creates mosquito and files problems and also causing deterioration to river water quality. various methods are available at the moment for reduce this problem and one such method is storm water drain design.

In hydrological analysis, various studies are carried out on storm drainage design one of the study by Mr.Altaf hussain (2016) Rectangular cross-sections of drains for three catchments were designed using Manning's equation according to peak discharge. P Sundara Kumar(2015) make model which utilizes the rainfall in design storm water drainage system. T. Siva Subramanian,(2014) found that Remote Sensing and GIS is a useful tool for spatial planning of storm water issues. I. N. Tziavos(2016) determined parameters that are important to consider in deriving a DEM error budget. Specifically, terrain slope, land-cover type, information loss, and data measurement schemes. Harshil $\mathrm{H}$. Gajjar(2014) designed diameter of pipes as well as discharge of pipe at jodhpur-Ahmedabad Needhidasan.S and Manoj Nallanathel (2013) storm water drainage design at kerala. Keshav Basnet and Keshav Barnet (2017) analysis area of Pokhara, Nepal and design side road drain system as well as upgrade the existing drainage system. Priyanka D. Harpalani(2013) develop rainfall intensity vs duration and design of drain is carried with help of Manning's chart in study area. Ankit Balvanshi and H.L. Tiwari(2014) The Natural Resource Conservation Service curve number technique is very helpful tool for estimation of direct runoff from storm rainfall. Bangar Sunil. R, Patil Pramod. Z and Kashid Vinod(2018) the details methodology to prepare plan for watershed development of a village.

\section{OBJECTIVES}

1. To understand existing drainage system and relevant problems of Navrangpura.

2. To understand the rainfall pattern and respective runoff generation by analyzing previous years data.

3. To analyse and design the drainage system of Navrangpura, Ahmedabad.

\section{STUDY AREA}

The geographic location of the Navrangpura area is located in Ahmedabd district of Gujarat state and lies between latitude $23.036706 \mathrm{~N}$ and longitude $72.561066 \mathrm{E}$. The geographical area of Navrangpura is $11.98 \mathrm{Sq}$. Km. The months of April to June are the summer months with the temperature ranging from a minimum of $27{ }^{\circ} \mathrm{c}$ to $44^{0} \mathrm{c}$. The temperature during winter months ranges from $27^{\circ} \mathrm{c}$ to $16^{\circ} \mathrm{c}$. The annual rainfall in the region is about $772 \mathrm{~mm}$ and is contributed by the southwest monsoon. The average number of rainy days is 34 in Ahmedabad. Excessive falls of rain during June to August cause frequent floods in the rivers and canals submerging low lying areas. Navrangpura area is located on banks of Sabramti river. This area is at the center of ahmedabad. Navrangpura is considered as the educational and commercial capital of Gujarat .

Vary famous colleges in each and every field are in this area like M.G.Science, L.D. College of engineering and technology, GLS law college, CEPT University etc.Very well known saloons, shopping malls, hotels, restaurants, hospitals and cafes are in this area. Big projects like METRO is going on in this area Gujarat government gives higher focus on this central area.In the field of Infrastructure development this area also contribute more in ahmedabad city. The key plan of the study area is shown in the figure 1 .

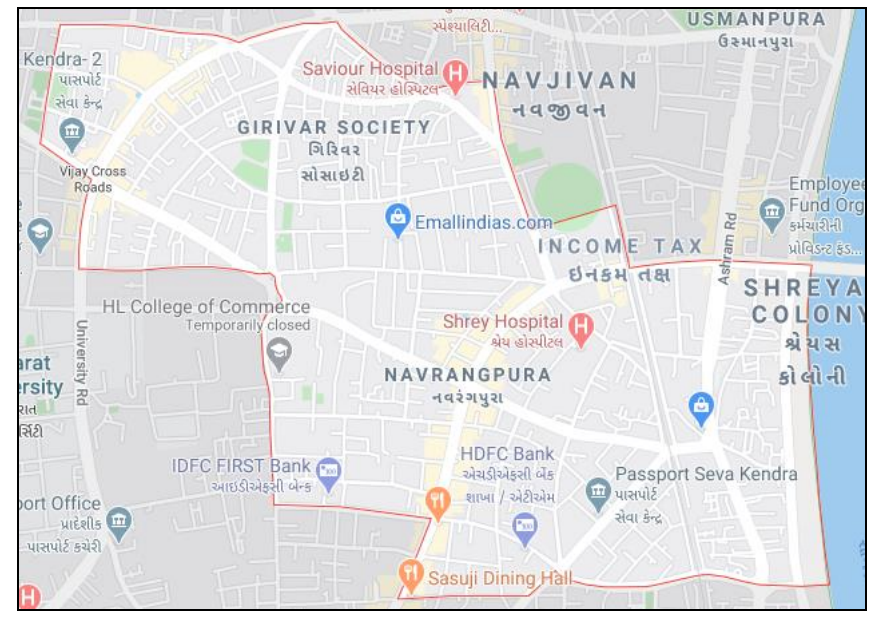

Figure 2: Study Area

The main reason for the problem to be so acute is the poor drainage network in the area. Absence of drainage network also results in the indiscriminate discharge of wastewater into the water bodies. The storm water during the heavy rainfall in the area leads to block the roadways, canals, and other sub roads which leads to interruption of traffic, transport, trade, education and other works.

\section{METHODOLOGY}

The field data required for the design of the sewerage system such as details of exiting water supply, the ward wise population as per census, development plan etc. were collected from the Navrangpura Municipal council. In the present study, rational method is used to estimate discharge for the Navrangpura. Discharge is a major input for the storm water design and also the Geographical Information of the city is essential to find out the general slope of the ground which helps in finalizing the alignments and directions of the sewers. Soil data was collected from the ICAR-National Bureau of Soil Survey \& Land Use Planning Regional Centre, Udaipur

Google earth pro is used in many field like

- Making movies with Google Earth

- Using layers 
- Using places

- Managing search results

- Measuring distances and areas

- Drawing paths and polygons

- Using image overlays

- Using GPS devices with Google Earth

- Tilting and viewing hilly terrain and many more.

\section{A. Area of Navrangpura with Google earth pro}

Take different pin points through pin tool and with various longitude and latitude mark points. After that choose polygon tool and join all points and get whole study area after completion of joining point we have various options like Style, color, view, measurement etc.

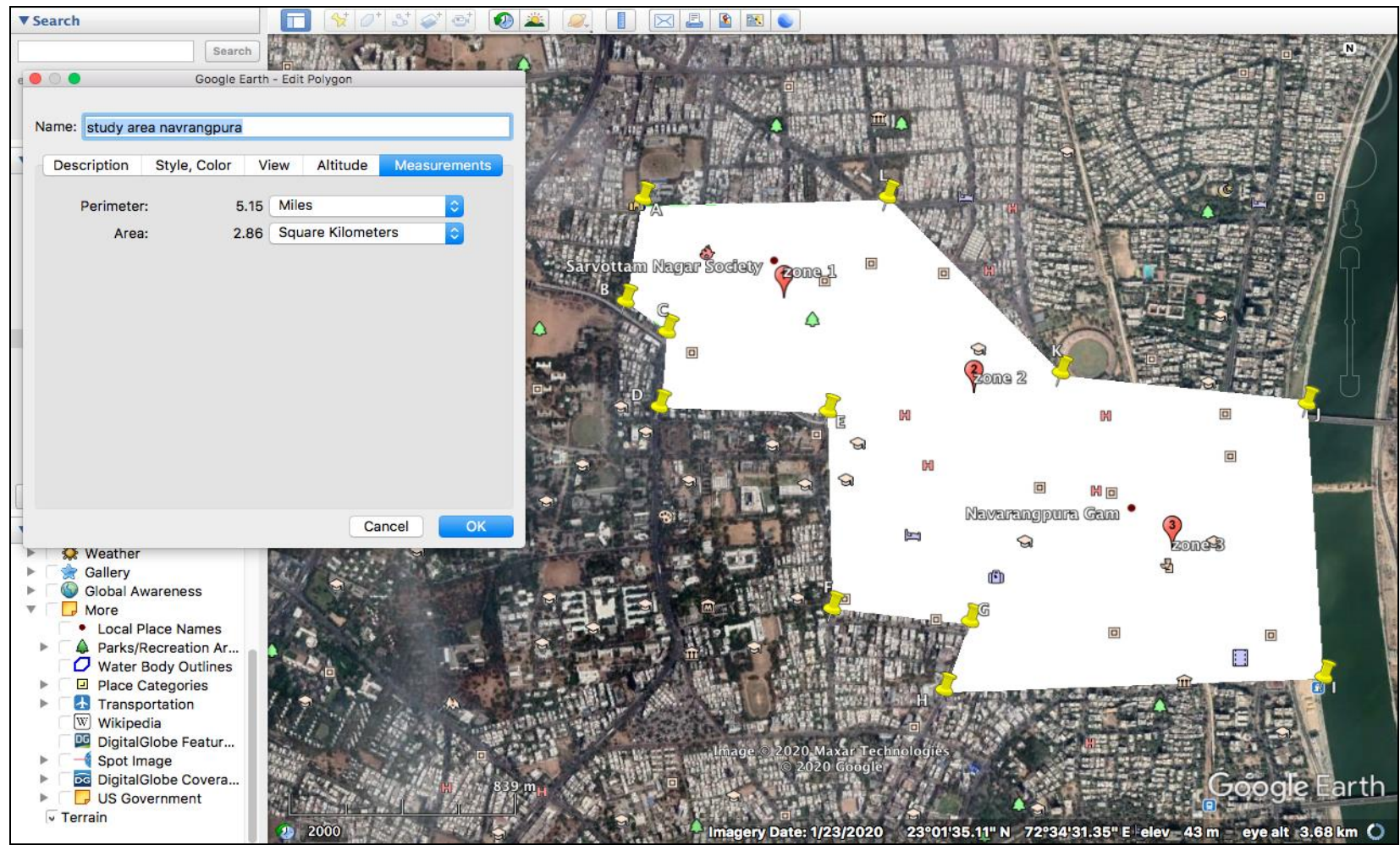

Figure 3: Area Measurement in Google earth pro

\section{B. Elevation Profile}

In this Google earth pro is used for measurement of elevation as well as elevation different of Navrangpura area. Whole area was divided into three zone and taken seven node points with the help of line tool create a line which join seven node points and through Show Elevation Profile option I got elevation of whole area which shown in below fig. 


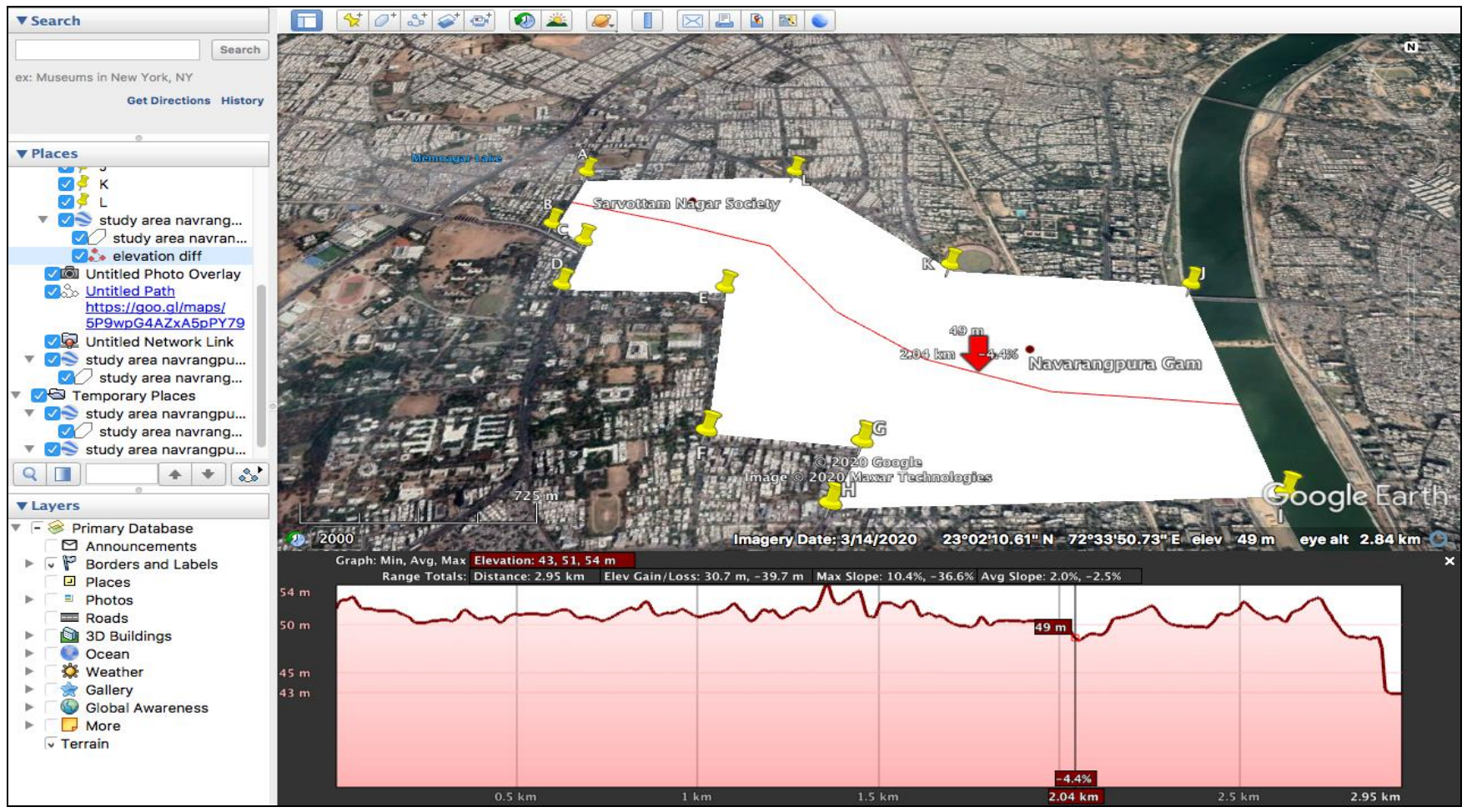

Figure 4: Elevation Different At Node Points

Table 1: Elevation of node points

\begin{tabular}{|c|c|c|c|}
\hline Node Points & Latitude & Longitude & Elevation (m) \\
\hline 1 & $23^{\circ} 02^{\prime} 44.6^{\prime \prime}$ & $72^{\circ} 32^{\prime} 52^{\prime \prime}$ & 52 \\
\hline 2 & $23^{\circ} 02^{\prime} 36.7^{\prime \prime}$ & $72^{\circ} 33^{\prime} 14.5^{\prime \prime}$ & 50 \\
\hline 3 & $23^{\circ} 02^{\prime} 32.9^{\prime \prime}$ & $72^{\circ} 33^{\prime} 25.8^{\prime \prime}$ & 54 \\
\hline 4 & $23^{\circ} 02^{\prime} 20.6^{\prime \prime}$ & $72^{\circ} 33^{\prime} 35.3^{\prime \prime}$ & 52 \\
\hline 5 & $23^{\circ} 02^{\prime} 10.7^{\prime \prime}$ & $72^{\circ} 33^{\prime} 46.3^{\prime \prime}$ & 51 \\
\hline 6 & $23^{\circ} 02^{\prime} 06.2^{\prime \prime}$ & $72^{\circ} 34^{\prime} 01.9^{\prime \prime}$ & 42 \\
\hline 7 & $23^{\circ} 02^{\prime} 02.2^{\prime \prime}$ & $72^{\circ} 34^{\prime} 20.7^{\prime \prime}$ & \\
\hline
\end{tabular}

The existing pipes of city from zone 1 to zone 3 carries maximum water and in rainy season the storm pipes and roadways both carries the high run off. This occurs because the inlet is insufficient to carry the initial discharge which truly affects the capacity of the pipe from zone 1 to zone 3 .

Table 2: details of the location of drains, time of concentration, runoff and slope

\begin{tabular}{|c|c|c|c|c|c|c|c|c|c|c|c|c|c|c|c|c|c|c|c|}
\hline $\begin{array}{l}\dot{z} \\
\dot{\vec{n}}\end{array}$ & 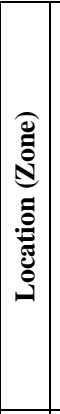 & 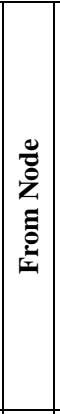 & 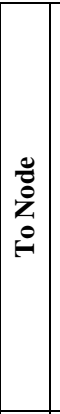 & 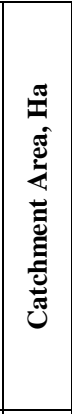 & 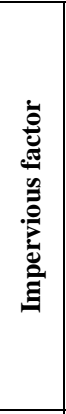 & 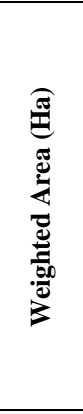 & 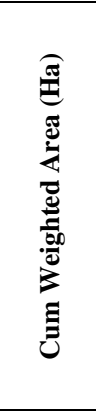 & 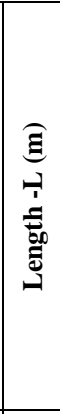 & 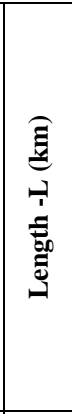 & 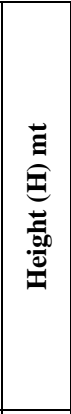 & 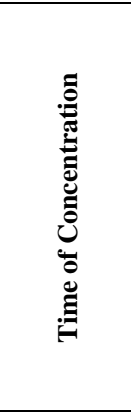 & 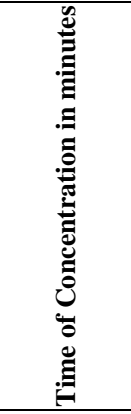 & 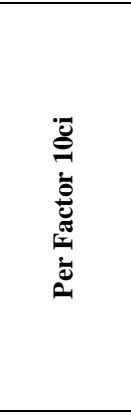 & 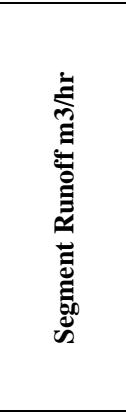 & 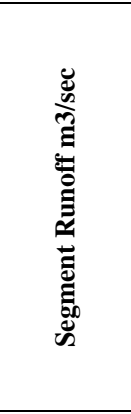 & $\begin{array}{l}\hat{0} \\
\stackrel{0}{0} \\
0 \\
\frac{B}{a} \\
\frac{B}{x}\end{array}$ & 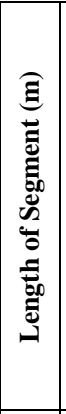 & 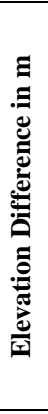 & 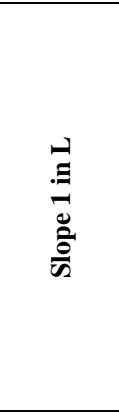 \\
\hline 1 & 1 & 1 & 2 & 30 & 0.5 & 15 & 15 & 459 & 0.46 & 2.00 & 0.385926 & 23.15555 & 367.9149 & 5518.723 & 1.532979 & 1532.979 & 459 & 1 & 0.002179 \\
\hline 2 & 1 & 2 & 3 & 32.9 & 0.4 & 13.16 & 28.16 & 416 & 0.42 & 3.00 & 0.346446 & 20.78675 & 381.3939 & 5019.144 & 1.394207 & 1394.207 & 416 & 1 & 0.002404 \\
\hline 3 & 2 & 3 & 4 & 52 & 0.4 & 20.8 & 48.96 & 429 & 0.43 & 2.00 & 0.233861 & 14.03165 & 430.4797 & 8953.977 & 2.487216 & 2487.216 & 429 & 3 & 0.006993 \\
\hline 4 & 2 & 4 & 5 & 38.8 & 0.4 & 15.52 & 64.48 & 444 & 0.44 & 2.00 & 0.28196 & 16.91758 & 407.1187 & 6318.482 & 1.755134 & 1755.134 & 444 & 2 & 0.004505 \\
\hline 5 & 3 & 5 & 6 & 72 & 0.5 & 36 & 100.48 & 573 & 0.57 & 2.00 & 0.495788 & 29.74726 & 336.6272 & 12118.58 & 3.366272 & 3366.272 & 573 & 1 & 0.001745 \\
\hline 6 & 3 & 6 & 7 & 60.4 & 0.4 & 24.16 & 124.64 & 602 & 0.6 & 3.00 & 0.248508 & 14.9105 & 422.892 & 10217.07 & 2.838075 & 2838.075 & 602 & 7 & 0.011628 \\
\hline
\end{tabular}


Table 3: Possible Discharge Calculations for different velocities at different sections

\begin{tabular}{|c|c|c|c|c|c|c|c|c|}
\hline Sr. No. & From & To & Diameter(m) & Area(m2) & V1 (0.3) & V2 (0.5) & V3 (1) & V4 (1.5) \\
\hline 1 & 1 & 2 & 1.25 & 1.227 & 0.3681 & 0.6135 & 1.227 & 1.8405 \\
\hline 2 & 2 & 3 & 1.25 & 1.227 & 0.3681 & 0.6135 & 1.227 & 1.8405 \\
\hline 3 & 3 & 4 & 1.5 & 1.767 & 0.5301 & 0.8835 & 1.767 & 2.6505 \\
\hline 4 & 4 & 5 & 1.5 & 1.767 & 0.5301 & 0.8835 & 1.767 & 2.6505 \\
\hline 5 & 5 & 6 & 2 & 3.141 & 0.9423 & 1.5705 & 3.141 & 4.7115 \\
\hline 6 & 6 & 7 & 2.5 & 4.908 & 1.4724 & 2.454 & 4.908 & 7.362 \\
\hline
\end{tabular}

Table 2 shows various details like weighted area, Time of concentration, Segment runoff, flow from different points and elevation different it is useful to find runoff from the zone to zone .

Table 3 shows the detailed design features of the drainage system. It shows the possible discharge generation at different velocities. As mentioned in CPHEEO manual and storm design manual the velocity may vary from 0.3 to $3 \mathrm{~m} / \mathrm{s}$. therefore at different points different velocities may be generated so discharge depending upon that.

\section{RESULTS AND DISCUSSIONS}

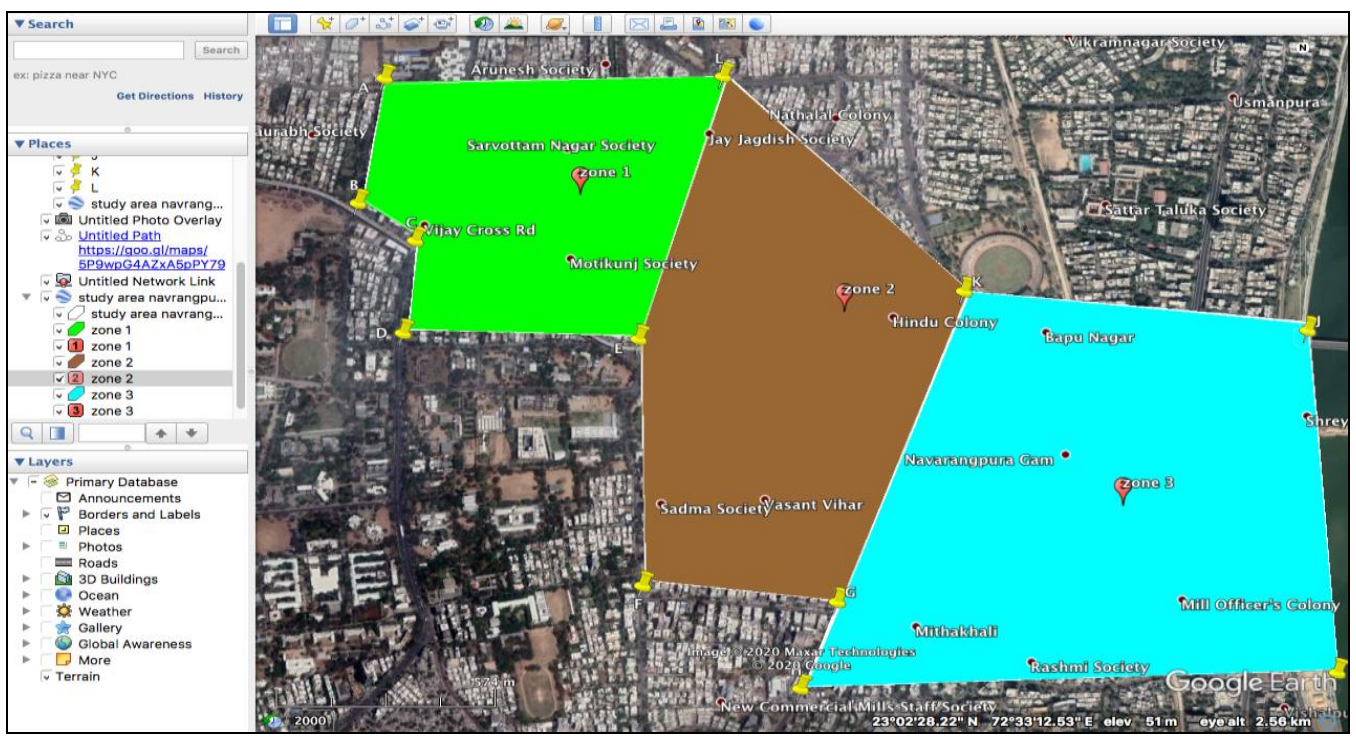

Figure 5: Zone division of Navrangpura area

Zone division has been done with considering geographical condition of this area and elevation different which already show in table 1. Existing drainage network of Navrangpura area has been surveyed, calibrated and corrected with the data provided by municipality. Drainage pipes were surveyed to obtain the growth truth and real data of Navrangpura area. The measured depth details cross -section and all the length were compared with existing maps of storm network. In manual design various aspects were related and considered.
Table 3: Zone wise runoff

\begin{tabular}{|c|c|c|c|}
\hline & & & \\
\hline 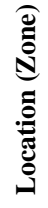 & 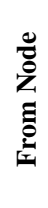 & 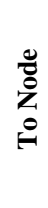 & 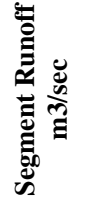 \\
\hline 1 & 1 & 2 & 1.5329 \\
\hline 1 & 2 & 3 & 1.3942 \\
\hline 2 & 3 & 4 & 2.4872 \\
\hline 2 & 4 & 5 & 1.7551 \\
\hline 3 & 5 & 6 & 3.3662 \\
\hline 3 & 6 & 7 & 2.838 \\
\hline & & & \\
\hline
\end{tabular}


All the required information like Area of Navrangpura, elevation profile and slope was found from the Google earth pro and analyze with the help of various formula.

\section{CONCULSION}

Navrangpura area is facing strom water drainage problem due to increasing population and infrastructural activities. The inundation of the study area is mainly due to the blockage of the drains in different points; therefore periodical maintenance of existing drains is essential. Google earth is software in which we can easily find area ,perimeter and elevation different . Rational method has been successfully used for the estimation of storm wise discharge in Navrangpura area. This study can be helpful to design storm drainage pipe at other places.

\section{ACKNOWLEDGEMENT}

The authors ate thankful to the State Water Data Centre (SWDC), Ghandhinagar for providing the rainfall data. The authors.

\section{REFERENCES}

[1] P Sundara Kumar,T Santhi ,P Manoj Srivatsav,S V Sreekanth Reddy." Storm Water Drainage Design (Case Study Vijayawada)" ,International Journal of Earth Sciences and Engineering (2015).

[2] T. Siva Subramanian, Tharini Cheyapalan, T. Selvaraj and Dr. V. E. Nethaji Mariappan "Mapping Storm Water Sewer System and using GIS", ADR Journals (2014)

[3] N. Nagarajan and S. poongothai "Spatial Mapping of Runoff from a Watershed Using SCS-CN Method with Remote Sensing and GIS" Journal of hydrologic engineering (2012)

[4] D. Bolkas, G. Fotopoulous, A. Braun,I.N.Tziavos" Assessing Digital Elevation Model Uncertainty Using GPS Survey Data" Journal of Surveying Engineering (2016).

[5] Harshil H. Gajjar and Dr. M.B.Dholakia "Storm Water Network Design of Jodhpur Tekra Area of City of Ahmedabad" International Journal of Engineering Development and Research (2014).

[6] Needhidasan.S and Manoj Nallanathel "Design of Storm Water Drains by Rational Method - an Approach to Storm Water Management for Environmental Protection" International Journal of Engineering and Technology (IJET-2013).

[7] Keshav Basnet and Keshav Barnet, "Storm Water Drainage Design Based on Hydrologic Analysis: A Case study Lamachaur CatchmentArea,Pokhara,Nepal" A journalof TUTA(2018.)

[8] Priyanka D. Harpalani, R.B.Khasiya and Dr.P.G.Agnihotri "Analysis of Rainfall Data and Design of Storm Water Drainage System in an Urban Area" GRA- Global Research Analysis(2013).

[9] Ankit Balvanshi and H.L. Tiwari " A Comprehensive Review of Runoff Estimation by the Curve Number Method" International of Innovative Research in Science, Engineering and Technology(2014).

[10] CPHEEO Manual, Manual on sewerage and sewage treatment (second edition). 